\title{
7
}

\section{Mentoring in Practice: Rebuilding Dialogue with Mentees' Stories}

\author{
Laure Kloetzer, Jo Wells, Laura Seppänen, \\ and Sarah Hean
}

\section{Introduction}

This chapter reports on an intervention in organisational learning and innovation conducted in 2019 with a Voluntary and Community

L. Kloetzer $(\bowtie)$

Institute of Psychology and Education, University

of Neuchâtel, Neuchâtel, Switzerland

e-mail: laure.kloetzer@unine.ch

J. Wells

Bournemouth University, Poole, England, UK

e-mail:wellsj@bournemouth.ac.uk

L. Seppänen

University of Helsinki, Helsinki, Finland

e-mail: laura.seppanen@ttl.fi

S. Hean

University of Stavanger, Stavanger, Norway

e-mail: sarah.c.hean@uis.no 
Sector (VCS) organisation in the South of England, active since 2005 mentoring ex-prisoners to support their (re)integration back into society. This intervention aimed at analysing the VCS activity and (re)building dialogue within the team. The organisation was seen by its staff as in a context of crisis. This was largely attributed to the uncertainties on funding and changing expectations of the role of the VCS within the Criminal Justice System in the UK. To support the (re)building of dialogue, the intervention hybridised the practices and methodologies of Change Lab and Clinic of Activity methods. The chapter first introduces the context of the intervention, secondly some methodological aspects of the intervention and thirdly the main findings of the researcher's empirical analysis of mentoring in practice. It will then discuss how these research data were used in a developmental workshop to support dialogue and reflection amongst staff members of the charity. The concepts of dialogical artefacts and micro-dramas will be used to analyse the dynamics at stake. We show that the researcher and practice participants have taken very different angles to make sense of the dialogical artefacts and micro-dramas presented to them. We finally discuss when and who should conduct the analysis of the research data collected from the workplace organisation, and drive problem identification required as a driver for future innovation.

In some research-led and more traditional interventions, the researcher conducts the analysis of research data and presents their findings to key stakeholders engaged in organisational learning, change and innovation activities — see for example design approaches (Penuel, 2014). They hope their analysis of the data will trigger dialogue between participants leading to cocreation and innovation. However, Sannino et al. (2016) claim that it is not for the researcher to make this analysis and hereby identify the problem embedded within the raw data collected from practice but the workers participating in the intervention themselves. This is at the heart of formative interventions such as Clinic of Activity and Change Laboratories, where mirror data selected from interviews and observations are brought to the developmental workshop. Here participants, in cooperation with the researcher and perhaps with the use of analytical tools such as theoretical frameworks, analyse the mirror data and draw their own conclusions of where problems in practice lie. In this 
chapter, we present evidence of this in a narrative in which the empirical analysis of the researcher and the later analysis of practice professionals engaged in a developmental workshop took very different turns. This contrast highlights the limits of researcher driven rather than researcher facilitated analysis of workplace data in the work development process.

\section{The Involvement of the Voluntary Community Sector in Criminal Justice}

The VCS has a long and well-established history of supporting prisoners and ex-prisoners in the criminal justice systems of Britain and the USA (Bryans et al., 2002; Epstein, 2009; Hughes, 2016) and VCS organisations have been piloting projects to support individuals in the community "at risk of reoffending" since the 1970s. These have ranged in scope from radical projects such as the Newham Alternatives Project (Dronfield, 1979) to "Community Chaplaincy" interventions (Whitehead, 2011). In the 1990s, the VCS became viewed as key partners in the core business of crime reduction (Tomczak, 2016). Clinks (an infrastructure organisation supporting voluntary organisations in the criminal justice system in England and Wales) was established in 1998 to support, promote and represent the involvement of the VCS in the criminal justice system (Gojkovic et al., 2011). Such projects raised questions about the efficacy and gaps within public sector offender rehabilitation. It has been argued that the VCS filled a particular gap left in England when probation services moved away from their traditional values of "advise, assist and befriend" towards a more "managerialist" and risk-driven agenda (Robinson \& McNeill, 2013; Hucklesby \& Wincup, 2014). In 2013, the Ministry of Justice announced a "Rehabilitation Revolution" which promised support to "anyone who had spent a day or more in prison", commissioning services from a competitive pool of commercial and VCS organisations. The Transforming Rehabilitation Act came into force in 2014 (Ministry of Justice, 2013). Whilst smaller organisations expected funding from the state as a result of this legislation, most were in fact almost side-lined, when large contracts were divided out across the country between the bigger charities and 
private companies called CRCs (Community Rehabilitation Companies). Following a number of reports on the limits of this system, National Probation Services are to take back the supervision of all offenders from December 2020.

\section{Benefits and Risks of Through-the-Gate Mentoring Schemes}

The VCS offers mentoring schemes, amongst other services, across England and Wales, mainly helping those leaving custody to resettle back into the community (Hinde \& White, 2019; McNeill, 2019). Mentoring encompasses a range of different activities occurring in different contexts. A consensual definition describes mentoring as a "one-to-one relationship which is freely entered into and based upon trust and confidentiality. Mentoring is distinct from befriending in that it involves working to clearly defined goals and within set time frames" (Hucklesby \& Wincup, 2014, p. 376). In the UK, mentoring has become routine criminal justice practice, despite some lack of demonstrated outcomes in reducing reoffending (Newburn \& Shiner, 2006), and is a strategic priority in policy aimed at reducing reoffending (HM Government, 2019).

The increase in VCS mentoring schemes, and other offender-related services, are argued to be a response to public sector "austerity cuts" and marketisation agenda (Hucklesby \& Wincup, 2014, p. 374). According to Hucklesby and Wincup, current mentoring policy "brings a group not currently subject to supervision under the gaze of the state" (ibidem, p. 375). They conclude with "the paradox inherent in using mentoring within the criminal justice: on the one hand, it (mentoring) might assist offenders to deal with long-standing problems but on the other hand, it provides a vehicle through which the formal criminal justice system can deepen its involvement in offenders' lives" (p. 375).

In summary, mentoring schemes, and VCS organisations across the UK, face a complex working environment, one in which they need to learn, innovate and develop to respond to the current demands and challenges placed upon them. In this chapter we present the potential of interventions designed to promote these processes. 


\section{Intervening in a Context of Crisis}

This intervention took place within a VCS organisation in England, which had extensive experience in mentoring ex-prisoners, with complex issues locally. Prior to the Transforming Rehabilitation agenda, this organisation had a memorandum of understanding with local prisons allowing staff and volunteers to take referrals from prison, assess prisoner's needs and support their preparation for release. Typically, volunteers would meet people at the prison gate and accompany them in the days, weeks and months following release. The organisation's beneficiaries were often of low socio-economic status, with limited work qualifications and employment history. Many of their beneficiaries reported childhood neglect, abuse and being expelled from school. Many had never owned a home, or even held a tenancy. A majority had serious substance misuse issues, many were physically dependent on alcohol or opiates. At least half of them had health problems, either mental or physical, often both. The mental health issues included autism, personality disorders, severe trauma and Post Traumatic Stress Disorder. These were further compounded by learning disabilities — typically dyslexia—or behavioural disorders such as ADHD.

Since its beginnings, the financial situation of this VCS organisation had been uncertain, due to the lack of regular funding for its mentoring activity. They continued to support their clients, whilst simultaneously seeking to develop and innovate, imagining new projects for the future and finding ways to find its place in the landscape created by the Transforming Rehabilitation agenda. The context of mentoring was changing, from mentoring independently from any institution on a volunteer basis, to diverse mentoring schemes in diversion or community sentence schemes. These changes of context for mentoring created tensions/challenges for the team, and the mission of their volunteers.

In this context, interventionist researchers with whom the organisation had contact through a wider research-practice partnership (an EU funded project, COLAB-H2020-MSCA-RISE-2016/734536), suggested an exploration of the views of different stakeholders within the organisation (trustees, staff members, volunteers and beneficiaries) 
on the organisation as it is and could be in the future. This culminated in a workshop with staff, supporting them to collectively reflect on the current context and contradictions/tensions arising. These reflections would contribute to moving beyond its impasse and develop plans for the future with service redesign.

\section{Conducting a Hybrid Change Lab/Clinic of Activity Intervention}

The intervention was inspired by the theoretical and methodological frames of Cultural-Historical Activity Theory (CHAT), especially Clinic of Activity (Clot, 1999; Clot \& Kostulski, 2011) and Change Lab (Engeström, 1987; Engeström et al., 1996; Sannino \& Engeström, 2017). Common to both these approaches is the use of facilitated and collective meetings between key stakeholders to discuss and design means of organisational change (see Chapter 8 of this volume). This workshop was preceded by an ethnographic phase in which mentors were observed by the first author in their everyday activities, and in which the experiences of different stakeholders, including staff, volunteers and beneficiaries, of working with and for the organisation were explored in interviews. The process was supported through extensive field notes. Observations gave the researcher access to many interactions between staff or volunteer mentors and their mentees in various places: For example, the first author observed first meetings between a mentor and a potential mentee; assessment of mentee needs, in prison and after release; planned regular meetings with mentees in public places; emergency interventions with a mentee; interactions through phone or WhatsApp; reporting of these interactions in the organisation's digital data information system. Additionally, 19 interviews were conducted with mentees $(n=4)$, mentors $(n=5)$, trustees $(n=3)$, staff $(n=5)$, external partners $(n=2$ - police staff and an expert from the mental health hospital). The interviews were based on a narrative format around a few leading questions (beginning with their own experience with the charity). The questions aimed to understand these stakeholders' experience within this VCS organisation, and their 
understanding of its mission and current challenges. All interviews were audio recorded and transcribed.

All data were thematically analysed based on repeated readings and comparisons of the transcripts. The analysis was discussed as fieldwork dialogues (Lassiter, 2005) in the research team. The VCR (Voice, Centred, Relational) method of data analysis (Brown \& Gilligan, 1991, 1992) was also used for highlighting the perspective of the mentees. The analysis assumed each "person's voice" to be "polyphonic and complex" (Brown \& Gilligan, 1992, p. 15), which means that an individual might experience multiple, sometimes contradictory ways of thinking about and understanding situations (Brown \& Gilligan, 1992). How a person speaks (and indeed, does not speak) of their experiences, themselves, others and relationships, provides insight into their perceptions and experiences (Brown \& Gilligan, 1991, 1992; Doucet \& Mauthner, 2008). Early presentations of the work-in-progress with some members of the organisation's team, in a research seminar at the University of Neuchâtel, as well as ongoing informal conversations with team members and academic colleagues, helped us explore and develop these contradictory interpretations.

The whole process was guided by an interventionist perspective aiming at supporting learning, dialogue and collective reflection within the organisation. The analysis simultaneously contributed to our academic knowledge of the role of the mentor in the VCS and to this transformative purpose.

Ultimately, some data were selected to stimulate discussion between staff members, that could eventually lead to organisational learning and innovation. The forum for this discussion was a developmental workshop, designed to offer conditions for authentic and truthful dialogue within the team. 


\section{Research Findings from the Analytic Phase: Mentoring in Practice}

Based on data collected from interviews and observation, we, as researchers, analysed mentoring as an activity, in which the interplay of practical help and human sustained contact is critical. Our analysis highlights five dimensions of mentoring within this organisation from the experiences of mentors and mentees. Mentors' experience shows the challenges of working independently, in an uncertain world, whilst having to manage their emotions and establish boundaries between their personal and mentee's lives. Mentors describe mentoring as a "firefighting exercise" addressing the basic needs of sometimes desperate people-or people in desperate situations. Additionally, the analysis of the experience of the mentees highlights the benefits of this activity; mentoring is seen as a friendly presence, which helps meet basic needs with a human touch and serves as a bridging activity to navigate the complex ecology of services and institutions. These findings echo the challenges and benefits identified by Gosling and Buck (2015), stating that "mentoring may offer a safe space for mentees to practically 'try on' desistance for size, alongside a supportive other".

\section{The Need for Mentors to Work Independently}

Some mentors expressed doubts, lacking self-confidence regarding their mentoring. These doubts and feelings seem to be linked to limited training as well as to the need to work on their own, in relative isolation. For most volunteers, the criminal justice services have been a "black box" until they began mentoring their clients. They don't know much about the way criminal justice services are working, and have to discover and learn a lot. The need to meet and discuss with more experienced peers is reinforced by the concrete and emotional complexities of the situations of the mentees, and the ambiguity of the object of their work (Table 7.1). 
Table 7.1 Illustrative quotes regarding: working independently

\begin{tabular}{ll}
\hline & Representative comments \\
\hline $\begin{array}{l}\text { Uncertainty, lack of self-confidence, } \\
\text { lack of feedback }\end{array}$ & $\begin{array}{c}\text { "Most difficult I think it's really } \\
\text { being isolated being a volunteer, } \\
\text { because you don't really have any } \\
\text { feedback on what you're doing } \\
\text { and as I say you're just not really } \\
\text { sure what you're supposed to be } \\
\text { doing" } \\
\text { "I would like to have more } \\
\text { interaction with other volunteers. } \\
\text { I think I would have found it } \\
\text { useful for other volunteer's view } \\
\text { of how they handle strategically } \\
\text { the, the relationship with their... } \\
\text { with their clients" } \\
\text { "I didn't know how prisons ran, I } \\
\text { didn't know anything at all, and } \\
\text { it's quite an eye-opener. (...) They } \\
\text { would really open up to me and } \\
\text { tell me, you don't realise just how } \\
\text { some people have to live, do you, } \\
\text { until you work with them?" }\end{array}$ \\
justice system &
\end{tabular}

\section{The Emotional Labour of the Mentor and Their Need to Maintain Boundaries}

Mentoring in this context means working with people, whose life trajectories have usually been extremely harsh. Mentors reported being emotionally affected by mentees life stories and current circumstances which demand, paradoxically, both regular engagement and personal distance as well as acceptance of one's own limited power to act. Getting this personal distance right is one goal in the training of professional social workers, as well as recurrent difficulty in their professional life. Although it is one main focus of training VCS mentors in this context, it is challenging to get it right in the short training time and limited supervision possibilities of volunteers. Establishing and maintaining correct boundaries is one major difficulty raised both by volunteers and by staff supervising them. The need to "create distance with warmth, empathy and respect" is systemically talked about by staff members. They speak of the difficulty of understanding and establishing boundaries, whilst 
creating a "therapeutic alliance", which allows mentee and mentor to work together.

Interview data described a need to establish clearly mentors' expectations versus outcomes. Mentors talk of "learning to redefine success", a need to pursue mentoring despite frequent reoffending. Desistance was not seen as a linear path, but one paved with breaks and failures. Becoming aware of the extreme psychological and material difficulties of their mentees, helped mentors cope with the uncertain outcome of their efforts (Table 7.2).

\section{Mentees Need Practical Help and Social Recognition}

Mentoring was seen by both mentors and mentees first and foremost as an activity to meet the basic needs of people who are in a desperate situation. Basic needs include food, clothes, a roof or sleeping bag if no roof is available, engaging with health services and probation officers. Mentors also helped beneficiaries meet their legal and medical appointments and get access to welfare payments, identity documents, addiction or health services. The mentor also helped with emotional need such as a beneficiary's need for feeling socially acceptable, and having someone who cares, someone to talk to:

"Support, practical support, can help with lots of things from forms, phone calls, all the way down to just an ear to listen, and this is good for some people. People who don't really have family, I think sometimes just want someone separate to their life to offload, does that make sense? I think you've got probation but like again, sometimes you have this barrier with probation, you're scared to tell them everything, you know, but with them, you're not, because you can trust them" (mentee).

Helping with emergencies and providing social recognition and support go together. This is new for some of the mentees and helps in improving their self-esteem:

"Over the years, with getting in trouble and conviction, things like that, I've kind of alienated myself from my family a bit and all my friends are addicts so I haven't really got a lot of good friends that I can trust so it's nice to have (mentor's name) as somebody that I can call or meet up 


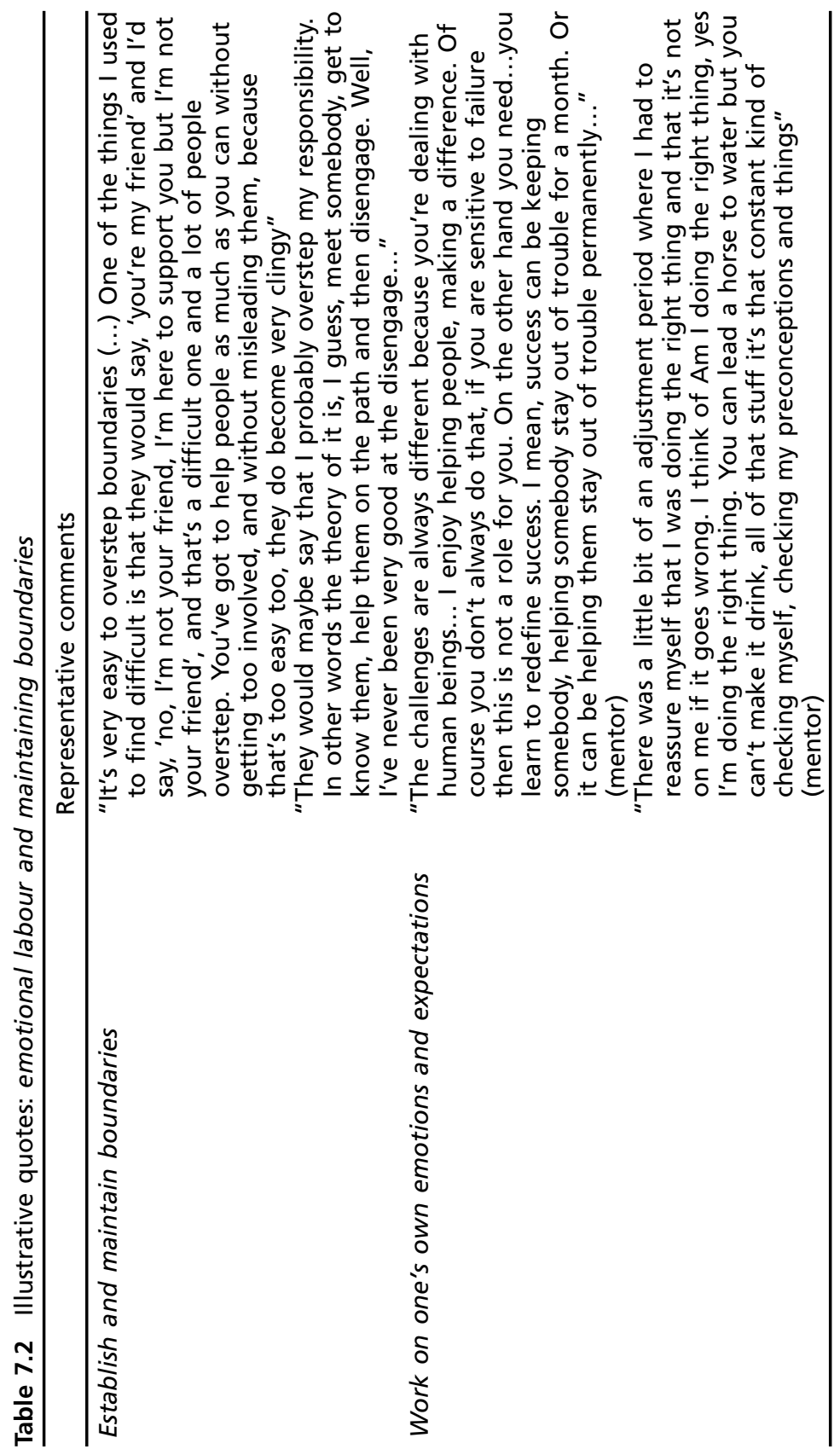


with to have a social chat, a coffee. (...) I have a really good relationship with my mother now and (mentor's name) sort of egged me on to do that as well, so he's a good guy. He motivates me, makes me feel good about myself" (mentee).

Mentors are described as providing sound advice in delicate human situations, a valuable resource for people who have no family nor reliable friends.

"Some of what we do as mentors, if you like, is provide conventional solutions to people for whom conventional solutions are not necessarily their first port of call" (mentor).

Keeping away from prison requires (at least partially) the acceptance of dominant social norms. We hypothesise that the personal, trusting relation patiently established between mentor and mentee through their practical engagement with multiple everyday emergencies, makes this (re)connection with the dominant norms possible. In this regard the dominant norm is not only the oppressive norm of the authority, but can be partly appropriated by the mentee because it is expressed and enacted by someone they trust (i.e., the mentor). "Providing conventional solutions", as stated above, the interactions between mentee and mentor implicitly initiated a re-normalisation process based on trust and not fear.

\section{The Importance of the Mentor in Assisting in and Navigating Complex Systems}

Mentees have multiple needs which are dealt with by a variety of diverse organisations including commercial companies, public services, charities, churches (soup kitchen, homeless shelters, laundry, meetings of Narcotics Anonymous, hotlines, etc.). The mentors utilise their own knowledge and social skills as well as the VCS' connections to identify these diverse resources and then navigate and liaise with these complex services with the support of the mentor. Mentor help is especially appreciated in interactions with public services, where the VCS reputation and status allow them to advocate for the mentees. In the complex ecosystem of social support for vulnerable people and criminal justice services, mentors play 
an important role because they are close to the service users and able to navigate this ecosystem efficiently. Their action aims at overcoming the silos of these services and fill in or supplement any shortcomings in their current service offer. One staff member defines their action as "helping an individual to engage with all of the services that they do need" (Table 7.3).

The importance of mentoring lies precisely in the capacity of the mentors to take the side of their mentees, meet them on their terms, whilst navigating the complex official system of institutions and programmes. Another staff member defines their action as "not providing the services, but providing the glue to the different services they need". They liaise in a way that considers the psychological fragility of their mentees.

Mentoring is well-recognised and appreciated by the mentees, as well as by partner organisations. Knowledge of local systems and advocacy skills, especially with public agencies, go hand-in-hand with a sound understanding of the delicate psychological condition of mentees. This liaison, orientation and navigation work begins from the prison gate and continues for as long as the mentees are not able to handle these tasks independently.

\section{Conclusion on Mentoring in Practice}

Overall, the researchers' analysis of data showed the benefits of mentoring to be multi-layered. The mentor was important for:

(a) meeting clients' basic needs (food, accommodation, health and medication, clothes, communication...)

(b) helping them with administrative procedures (Universal Credit, Identity documents, registration with a General Practitioner, bank accounts, housing, etc.) and advocating for public services

(c) helping with job searches, using computers, budgeting, etc.

(d) helping clients with keeping track of their life, especially keeping important appointments (probation and health appointments) and getting organised

(e) socialising, getting out regularly, meeting people in a positive manner 


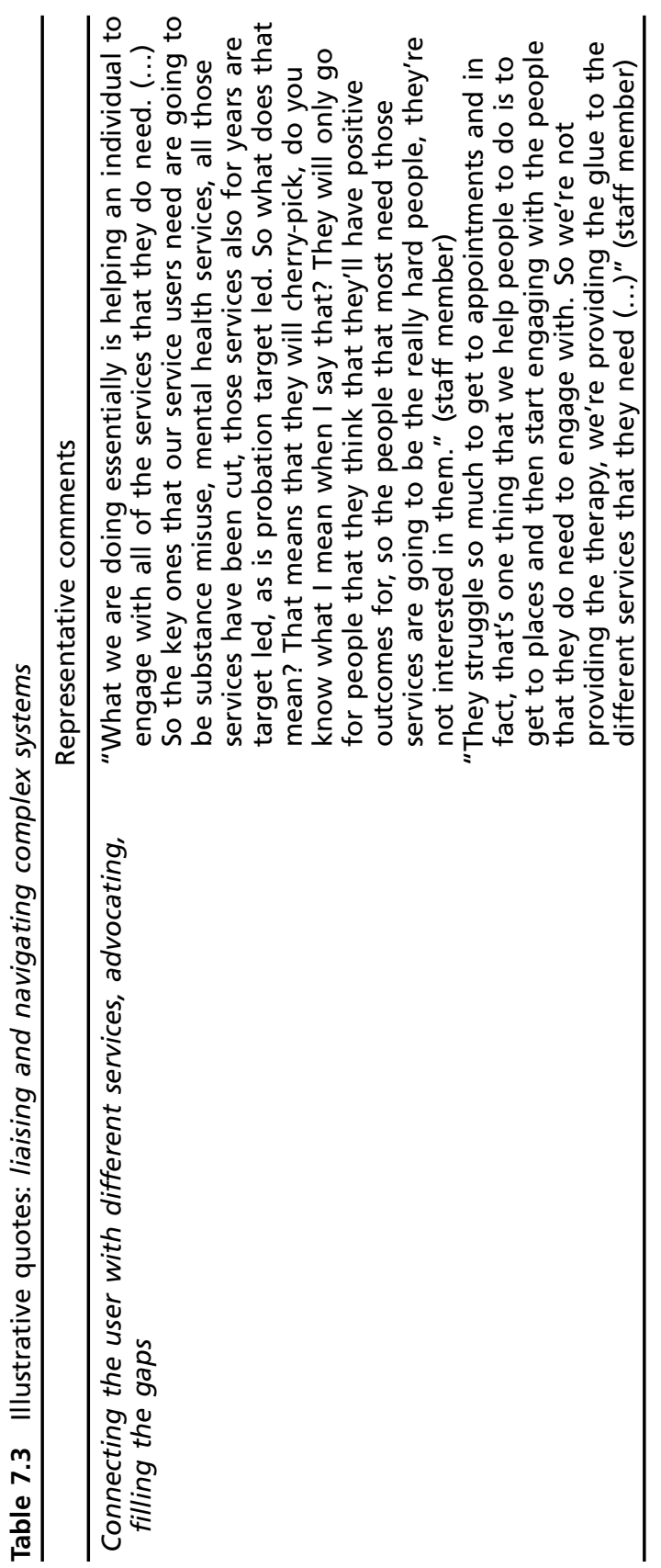




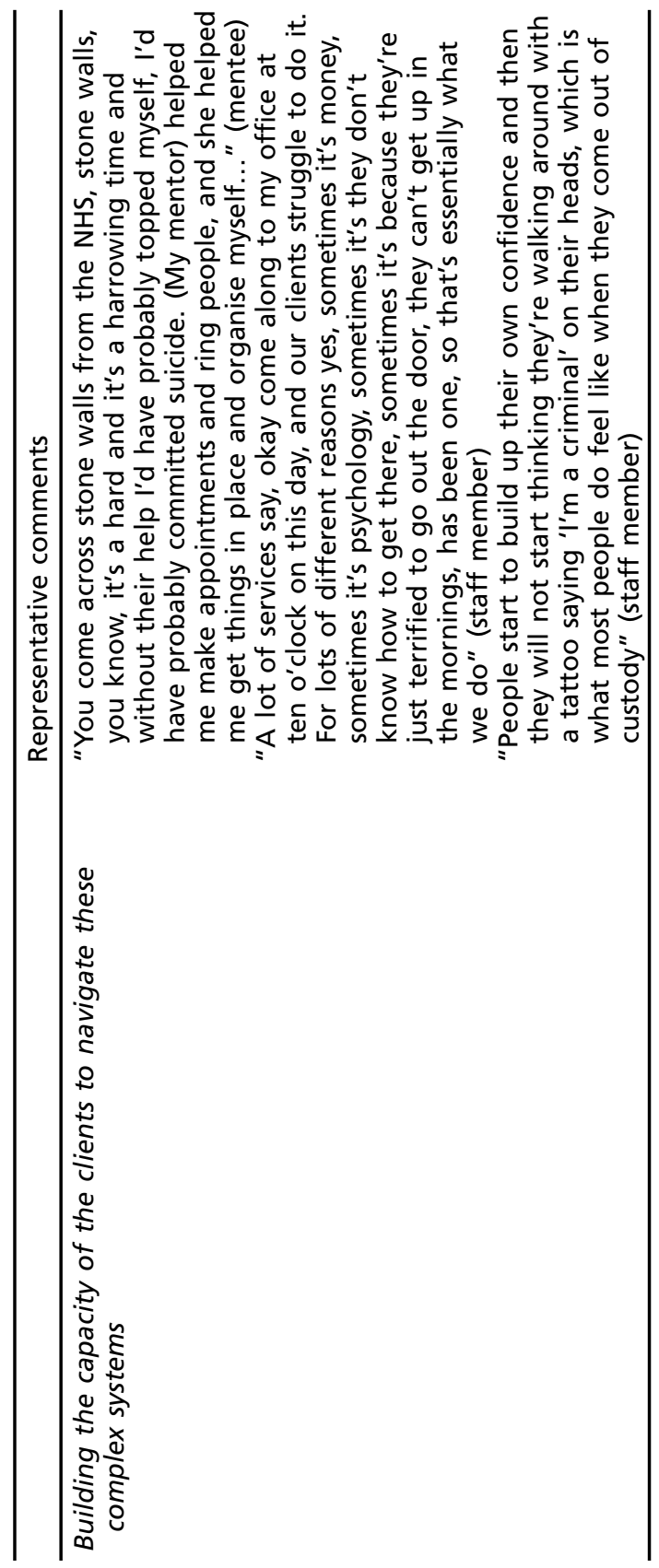


(f) listening to clients, offering social recognition and contact when friends and family are missing, reducing stress of life after prison, helping to see things clearer, helping to form judgement and to act according to the dominant norms of behaviour.

Our analysis demonstrates that the practical help (points a, b, c, d) and the social benefits (points e and $\mathrm{f}$ ) happen simultaneously and not independently, through the mentor providing the client with regular everyday support, with respect and human warmth.

\section{Rebuilding Dialogue Around Mentees' Stories}

\section{Users' Stories as Dialogical Artefacts}

The data collected not only served to build our understanding of the role of mentors in the criminal justice system, but also served as a trigger for dialogue in a service development workshop involving organisational staff. The key question for the researchers as interventionists was then to decide which aspects of the analysis would best support the collective reflection of the staff. The challenge was to identify, in the empirical data collected, some "elements" around which a special kind of professional dialogue-precise, documented, authentic, possibly controversial but respectful-could happen. The first phase of the research had demonstrated the strength of personal engagement of the mentors (volunteers and staff) with the former prisoners. Although different members of the organisation could hold sometimes divergent ideas on what the organisation should be doing in the future, their commitment to the mentees, the raison d'etre of the organisation, was unquestionable. In informal exchanges and interviews, they expressed recurrent questionings like: why do some mentees engage with us in the long term, and why do some mentees give up so quickly? Are our services appropriate for mentees and how? Therefore, when we had to select some materials to trigger collective dialogue and reflection, the first author decided to build short mentees' stories based on excerpts from the interviews. 
These stories were built by selecting in the interviews all parts dealing directly with mentees/mentors relationship. In theoretical terms, these stories are dialogical artefacts (Kloetzer, 2018), i.e. edited research data turned into polyphonic materials, which crystallise the multiple voices and reflections of interviewees, and capture some of the dialogues previously held in the course of the research. In our case, the mentees' stories present the own voice of the client, but also reflect indirectly the voices of the others, whom the client has been interacting with-voice of the mentor, of the doctor, of the probation officer, of the judge sometimes. All pieces of data telling about interviewees' relationship to the VCS organisation were included, so that the researcher did not attempt to write a coherent story. Four mentee's stories were constructed for intervention purposes.

Six staff members of the organisation attended the research workshop. The workshop was structured in the following way: first, we shared homemade sandwiches and a cup of tea, then the first author framed the purpose of the workshop, and gave an introduction to some CHAT core theoretical concepts, including the concepts of "activity systems" and "contradictions within the activity system and between activity systems" (see Chapters 2, 3, 5, 6 and 8 of this volume for further detail). Introducing this theoretical model provides a "second stimulus" to help the team take some distance with its own situation and analyse it, using this theoretical lens. The first author also explained how these concepts related to the practice of the organisation, studied in empirical work. Secondly, the researcher briefly presented the empirical work. Thirdly, she introduced the method chosen for the discussion, which was to first read and then discuss each of the mentees' stories. The Clinic of Activity approach uses data (sometimes videos, sometimes narratives, sometimes excerpts of reports) to support the analysis by the workers (here, VCS staff and volunteers) of their own activity in a polyphonic way. We explained how the content of the mentees' stories had been selected; i.e. by extracting in the interviews with the clients all comments which directly referred to their interaction or experience with the organisation under study. We then gave these mentees' stories in paper form to each participant. The stories were discussed one by one and gave rise to vivid exchanges between the workshop participants. 


\section{Anchoring Dialogue in Micro-Dramas}

Table 7.4 illustrates one of the stories brought to the workshop, extracted directly from an interview with a client/mentee in contact with the organisation.

During the workshop, the mentees' stories play a specific role: each of the participants pick up these stories according to their own perezhivanie of the situation, in Vygotskian term (Vygotsky, 1994) which means, through the prism of their own cognitive and emotional experience of the situation (Veresov, 2016, 2017) (Table 7.5).

This excerpt is the beginning of the discussion of the first mentee's story. In this section, we analyse the dialogical dynamics of this excerpt. This analysis of the architecture and dynamics of the conversation is based on an analysis with interlocutory logic, which is described elsewhere (Kostulski, 2004). The discussion on the first story opens with a question from the researcher. The whole sequence selected is then driven by this initial questioning, which relates to "what is important in the service" according to the first mentee (Adrian). Interestingly, all participants contribute to the following discussion, although they pick up very different elements of the story. The story carries indeed potential for open interpretation, as it is very dense, rich, emotional and open to possible and ambiguous meanings. The first staff participant selects a sentence from the written text, which highlights his own priority in mentoring: talking to the people. He doesn't add any comment at this point. The second staff participant selects a different verbatim, "probation has a different agenda", reverts it and attributes it to the mentee in a propositional way: "he thinks that we've got a different agenda from probation"- through this inversion, probation becomes the reference and the organisation represents a deviation to this reference. The third intervention supports this second comment in an indirect way: "really interesting, isn't it?", which remains enigmatic at this point. The fourth staff participant adds her own answer to the initial question, with two quotes, "not being let down", "not having a family", which also refer, in our observation, to her own views on the mentees as having a hard and lonely life. At this point, this juxtaposition of quotes triggers a metacomment on what is happening in the meeting, i.e., that different people 
Table 7.4 Client Adrian-selected quotes from our interview

I met (staff member) actually while I was in prison because he goes into the prison to talk. So I filled in the leaflet and he came and saw me because I had no family, I was homeless before I went to prison, and I needed support. Funnily enough, I found the leaflet because they don't really clean the cells when people move in, and someone else in my cell had obviously had one, so that's how I found it. But I suppose if I'd have asked for one, I'd have got one, but I didn't know about it, so that was lucky. Well, it was all geared up for when I got out. I mean, I met him, I'd actually seen him meeting someone else about seven months before my release, so I spoke to him and he said, well I'll come and see you nearer the date. And then they had an open day in the education block where there were lots of different agencies, people from work and probation, and (staff member) was there. He had a bowl of sweets so I was eating the sweets [laughs], but and then when he did come for the appointment he said this is what I can help you with; life, work, help you get, lots of different things, support, and since I've been out I think it's been great. I had a period of time where I relapsed on the drugs and I wasn't really seeing him (...) because when you come out of prison you don't have much money, I had no clothes, (another staff member) bought me some clothes and a cheap phone with credit, and then after that, because there's Universal Credit benefit but it takes a long time. (...) Nine weeks to get my money so that's a long time, you know. So, in that time, they would get me a food bank voucher, I don't know if they still do it, they used to get an Asda voucher so you could get some food, little things like this. But also, in support, (staff member), he's just support... I just phoned him today because I was going to meet him after you but he's a bit busy so he's going to meet me tomorrow, but he could tell straight away because I'm bit upset today, having to move back and that. Because I have no family, see, no family whatsoever. The family I did have are dead and I've been on my own for many years in addiction, so it's nice to have... okay, probation is cool, but probation more have a set job, don't they? They have to lower the risk of me reoffending which is good, but someone like (staff members) maybe yourself, you're more support, practical support, can help with lots of things from forms, phone calls, all the way down to just an ear to listen, and this is good for some people. People who don't really have family, I think sometimes just want someone separate to their life to offload, does that make sense? (...)

I think you've got probation but like again, sometimes you have this barrier with probation, you're scared to tell them everything, you know, but with them, you're not, because you can trust them. Obviously, there's boundaries but you know they're there, but yeah, a lot of people that come out of prison are just left, a lot of people come out of prison in this country and are homeless straight away and there's no one there to help them. And a lot of people who've been in prison feel a barrier between authority. (...) I always did. I always felt like I can't talk to this person, can't talk to that person. I think I'm doing alright at the minute with (Charity name). I think I'm so glad they didn't close my case, because they could have, because I went missing for a while, but instead they just picked the support straight up, and it's nice isn't it? Because not looking for sympathy but in my life, you're used to people letting you down, but they don't let you down 
Table 7.5 Discussion in the workshop between staff following the individual reading of Adrian's story (excerpt)

1. R: So according to Adrian, what's important in (VCS name) service?

2. P1: "Having someone to talk to"

3. P2: He thinks we've got "a different agenda from probation" on the issues of offending

4. P3: This is really interesting, isn't it?

5. P4: "Not being let down, not having any family", that's what really jumped out at me. So it's interesting that we've all got different things that jump out at us isn't it? (nervous laughs)

6. P5: (Staff member) uses sweets to get people to do things

7. P6: That's a standard! (big laughs)

8. P4: Well I like the first sentence actually. "I met (staff member) while I was in prison because he goes into the prison to talk"

9. P1: I think this is a perfect scenario of a (Charity name) client from the beginning when we reach someone in jail

10. P6: I don't think so. I'd probably buy about one or two mobile phones a year and I've never, ever, bought anyone clothes, so that's definitely not

11. P3: Yes it's really interesting, it is really interesting about the difference between what he says. It's really, really interesting

12. R: What do you think is interesting P3?

13. P3: For me, I would almost cry that he didn't think we were interested in helping him stop offending, that to me-to me-is the core of what it is about, it's helping people progress away from the criminal lifestyle. But here for him he thinks that doesn't matter to us...

14. P1: Why do you think so?

15. P3: Because he said that we have a different agenda from probation, the whole agenda

16. P1: Ha...

17. R: It's interesting because you also picked this one, $P 2$, different agenda from probation?

18. P2: I did make a joke, but yeah, even if I go back in offending, I'll have people there who will still work with me so...

19. P3: Yes, which is a good tip. I think we do want people to feel we don't give up and that they can be honest

20. P4: Well personally I think we need to be different from probation because if we're going to be the same as probation then what are we doing?"

pick up different aspects of the situation. A nervous laugh shows some discomfort with this situation. The two following comments from two other members are jokes, probably aiming consciously or not at relieving the atmosphere. 
The opening of this workshop, from speech turns 1 to 7 , frames rather well the whole problem space, organised in tension between two agendas of rehabilitation: one focused on desistance from crime, the other one on step-by-step re-socialisation. The dynamics of nervous laughs/joke/laughs again is a pattern regularly met in Clinic of Activity interventions, which, in our experience, frequently sets the ground for a second round of deeper dialogue between the participants.

Indeed, in speech turn 8, P1 comes back with a subjective appreciation of the situation as being "a perfect case", which is immediately contradicted (also at the level of appreciation) by P6, who bases their disagreement on the action to "buy" things for the mentee (a phone, or clothes in that case). P3 once again supports indirectly P6's position by stating that this is really interesting. As an explicit disagreement, brutally faced by all participants, threatens the expansion and deepening of dialogue, the researcher makes another intervention, with a direct question at $\mathrm{P} 3$, aiming not at closing nor smoothening the disagreement, but at explaining the position of P3. P3's answer is very rich, because it conveys both an emotional reaction ("I would almost cry...") and a wellarticulated statement on the positioning of the charity. Speech turns from 12 to 16 serve to make the perspective of P3 explicit, for the benefits in particular of P1, which non-verbally marks in 16 that they now understand what was meant and visibly engage in thinking about this quote "not the same agenda" with a new perspective.

In speech turns 17 to 20 , the researcher directly addresses another participant to make their perspective more explicit, opening a new small space of discussion of P2, P3 and P4. P4's perspective is more clearly expressed on this topic on "not the same agenda" at the end of this sequence: "personally I think we need to be different from probation because if we're going to be the same as probation then what are we doing?” This speech turn is also interesting because it joins a subjective positioning and a well-articulated argument.

In the follow-up of this dialogue, not presented here, P1 will reflect aloud on the interpretation we should have of this quote "not the same agenda" for this participant, coming back to the written text and his own knowledge of the case. This shows that in this dialogical space, P3's perspective becomes part of the internal dialogue of $\mathrm{P} 1$, and that 
conversely, P1's internal dialogue becomes, through externalisation, part of the shared reflections of the team.

This sequence is an interesting example of how collective reflection may progress step-by-step with passionate participants, in a wellstructured dialogical space around well-designed dialogical artefacts (here, the mentee's edited stories). Disagreements are not ignored but turned, if possible, into motors of development. The sequence opens with the framing of the problem space, showing immediately how different perspectives on rehabilitation, closer or more distant from what how the agenda of probation is perceived, reflect the personal experience and priorities of the different participants. Thanks to the shared reference of mentees' stories which constitute micro-dramas and micro-crises "that we can define as 'micro social situations of development" (Veresov, 2016, p. 133), in the sense of Vygotsky, it expands into a deeper reflection on this topic.

\section{Analysing Data Collaboratively: An Analytical Mismatch for Potential Development}

As mentioned earlier, the data collected all along the research process had a dual purpose: a research logic and an intervention logic. In this chapter, on one hand, we have presented the findings on mentoring in practice coming from an analytical approach of our interviews. On the other hand, some of these research data, selected by one of the researchers, have been simultaneously used by this researcher in a developmental workshop to support the main goal of the intervention: to help the staff collectively reflect and discuss the past, present and future of the organisation and of their mentoring activity.

We argue here that although the analysis of the researcher and of the organisation participants was different, these parts relate, and in fact there are mutual benefits of combining both the analytic approach (the researcher-driven analysis) and the interventionist approach (the participant-driven analysis).

After the analysis of the data from the researcher's perspective, the value and sense of the organisation's service to its clients was clear for 
the researcher. The analysis of the activity performed by the first author through observations and interviews highlighted (a) benefits, as well as challenges, of the mentoring activity for this population on multiple dimensions (practical, social, emotional, etc.) as well as (b) the interplay between practical, emergency help and the higher-level social, emotional and cognitive benefits for the client, and finally, (c) the important role of the organisation in the ecology of CJS, helping its clients get access to highly specialised and compartmentalised public, private or third sector services (housing, work, health and mental health, etc.) - -i.e., the organisation played a boundary crossing role in the field of post-prison rehabilitation.

In a classical research, at that point, the researcher could wish to feedback these important findings to the participants in a final workshop. However, in the first author's experience, sharing the findings of a research with the participants does not help them much in actively engaging in collective reflection, organisational learning and organisational transformation. If the research is sufficiently good, these findings are rarely contested and usually accepted with benevolent attention and without follow-up. In fact, the reaction to the presentation of research findings (of sufficient quality) should be expected to reflect the kind of relations that the researcher has built with participants-trustful relations might allow for more discussions than would distrust or conflict. Here, the quality of relations that the researcher had tried to build with the participants was put into balance with the sometimes tensed and quite emotional disagreements within the team. Following Vygotsky's call for the use of indirect methodologies (Vygotski, 1997), the interventionistresearcher then decided to appeal to the common passion of staff for their clients to try and create a safe space for collective dialogue. To do so, the first author created dialogical artefacts, made of selected parts of the interviews with the mentees, in order to ground and nourish the discussion. From the researcher's perspective, these vignettes or user stories had made concrete or materialised the most relevant aspects of the mentor-mentee relationship, and beautifully displayed the core benefits of mentoring and the core aspects of the organisation's service that should be preserved and expanded in the future. The researcher expected to rebuild this shared understanding of the mission of the organisation with 
the staff during the workshop, based on close shared analysis of these multi-faceted stories.

Surprisingly then for the researcher, when these user stories were shared in the workshop, that these were instead read by the participants in an unexpected way. It seemed at that time that all participants were cherry-picking very different elements, expressions or sentences, from these stories, and that none of them focused on the three main dimensions identified by the researcher in her own analysis (i.e., multi-dimensional support, interplay of technical help and higher-level support and boundary crossing role of the organisation in the complex local ecology of CJS and support services). Interventions are full of surprises like this. Our point is not that participants should follow researchers' understanding, but that they are supported in taking steps in their own collective (and individual) trajectories. Researchers gain new understanding with these reactions (Engeström \& Sannino, 2010; Seppänen et al., Chapter 9 of this book). By attempting to understanding the mismatch between the researcher's and the organisation's perspectives/analyses deepens both the participants' and researchers' understanding of the situation.

The analysis of the dialogical dynamics in the first minutes of the discussion of the first user story presented here shows that this cherry-picking did not happen randomly, but echoed-refracted-the emotional experiences of the participants within the organisation. The dialogue, framed and sometimes made explicit by the interventionistresearcher, constructed stepwise a problem space which was very relevant for the organisation, and helped us jointly understand the contradiction between "being like or not being like" the probation services. The interplay of past experience, personal knowledge and values, affective elements and focused dialogue, allowed for the opening up of a collective space for thinking and reflection-not without tensions, of course. This intervention and the subsequent analysis therefore highlights the discrepancy between the "desk analysis" performed by the researcher on academic bases, informed by her own perezhivanie of the intervention process, and the analysis performed during the workshop, informed by the perezhivanie, lived experience, of the staff participants. Our analysis of these tensions contributes to highlighting why collaboration 
between researchers and practitioners, although extremely important, is also rather difficult. It highlights that in this research context, both development and analysis are non-linear, iterative, processes, dynamically integrating varying perspectives from all participants to the research.

If compared to a Change Laboratory or the related Change/Boundary crossing Workshop (Ala-Laurinaho et al., 2017; Seppänen \& Koli, 2010) methodologies, the hybrid method applied in this case has emphasised a radical shift towards polyphony or multi-voicedness about the intervention. There does not have to be any final, monolithic/coherent story to be told about the outcome: what is more valuable is what all participants can do with the collective and personal lived experience of dialogue-researchers as well as practitioners.

\section{References}

Ala-Laurinaho, A., Kurki, A.-L., \& Simonsen Abildgaard, J. (2017). Supporting sensemaking to promote a systemic view of organizational changes-Contributions from activity theory. Journal of Change Management, Published online 5 April 2017.

Brown, L. M., \& Gilligan, C. (1991). Listening for voice in narratives of relationship. New Directions for Child Development, 54, 43-62.

Brown, L. M., \& Gilligan, C. (1992). Meeting at the crossroads: Women's psychology and girls' development. Cambridge, MA: Harvard University Press.

Bryans, S., Martin, C., \& Walker, R. (2002). Prisons and the voluntary sector: A bridge into the community. Waterside Press.

Clot, Y. (1999). La fonction psychologique du travail. Paris: Presses Universitaires de France-PUF.

Clot, Y., \& Kostulski, K. (2011). Intervening for transforming: The horizon of action in the clinic of activity. Theory \& Psychology, 21(5), 681-696.

Doucet, A., \& Mauthner, N. S. (2008). What can be known and how? Narrated subjects and the listening guide. Qualitative Research, 8(3), 399409. https://doi.org/10.1177/1468794106093636.

Dronfield. (1979) Outside chance: The story of the Newham alternatives project. Radical Alternatives to Prison.

Engeström, Y. (1987/2015). Learning by expanding. Cambridge University Press. 
Engeström, Y., \& Sannino, A. (2010). Studies of expansive learning: Foundations, findings and future challenges. Educational Research Review, 5(1), $1-24$.

Engeström, Y., Virkkunen, J., Helle, M., Pihlaja, J., \& Poikela, R. (1996). The Change Laboratory as a tool for transforming work. Lifelong Learning in Europe, 1(2), 10-17.

Epstein, R. (2009). The voluntary sector in UK prisons. Butterworth Tolley Publishing.

Gojkovic, D., Mills, A., \& Meek, R. (2011). Scoping the involvement of third sector organisations in the seven resettlement pathways for offenders (Third Sector Research Centre, Working Paper 57).

Gosling, H. J., \& Buck, G. (2015). Mentoring: Crossing boundaries with care? Helena Gosling and Gill Buck consider mentoring within a criminal justice context. Criminal Justice Matters, 99(1), 22-23. ISSN 0962-7251.

Hinde, K., \& White, R. (2019). Peer support, desistance and the role of the third sector. The Howard Journal of Crime and Justice, 58(3), 329-348.

HM Government. (2019). Guidance: Mentoring services for people in prison and on probation.

Hucklesby, A., \& Wincup, E. (2014). Assistance, support and monitoring? The paradoxes of mentoring adults in the criminal justice system. Journal of Social Policy, 43(2), 373-390.

Hughes, E. (2016). Non-profit and voluntary sector programs in prisons and jails: Perspectives from England and the USA. In Voluntary sector in prisons (pp. 21-51). New York: Palgrave Macmillan.

Kloetzer, L. (2018). VET as transformative, collaborative research: Cross selfconfrontation, dialogical artefacts, and the development of organizational dialogue in a Swiss factory. Nordic Journal of Vocational Education and Training, 7(2), 63-83.

Kostulski, K. (2004). Développement de la pensée et du rapport à l'autre dans une interlocution: «est-ce que c'est un endroit pour poser un paquet de contre-rails?». Cahiers de Linguistique Française, 26, 113-131.

Lassiter, L. E. (2005). The Chicago guide to collaborative ethnography. University of Chicago Press.

McNeill, F. (2019). Pervasive punishment: Making sense of mass supervision. Emerald: Bingley.

Ministry of Justice. (2013). Transforming rehabilitation: A revolution in the way we manage offenders (Vol. 8517). The Stationery Office.

Newburn, T., \& Shiner, M. (2006). Young people, mentoring and social inclusion. Youth Justice, 6(1), 23-41. 
Penuel, W. R. (2014). Emerging forms of formative intervention research in education. Mind, Culture, and Activity, 21(2), 97-117.

Robinson, G., \& McNeill, F. (2013). Purposes matter: Examining the 'ends' of probation. In What matters in probation (pp. 292-319). Willan.

Sannino, A., \& Engeström, Y. (2017). Co-generation of societally impactful knowledge in Change Laboratories. Management Learning, 48(1), 80-96.

Sannino, A., Engeström, Y., \& Lemos, M. (2016). Formative interventions for expansive learning and transformative agency. Journal of the Learning Sciences, 25(4), 599-633.

Seppänen, L., \& Koli, A. (2010, February 10-12). Exploring work: Employee stories as tools for promoting workplace well-being. Paper presented at the Towards Better Work and Well-being. Proceedings: 98-104, Helsinki, Finland.

Tomczak, P. (2016). The penal voluntary sector. Taylor \& Francis.

Veresov, N. (2016). Perezhivanie as a phenomenon and a concept: Questions on clarification and methodological meditations. Cultural-Historical Psychology, 12(3), 129-148.

Veresov, N. (2017). The concept of perezhivanie in cultural-historical theory: Content and contexts. In Perezhivanie, emotions and subjectivity (pp. 47-70).

Singapore: Springer.

Vygotski, L. (1997). Pensée et langage (1934). Paris: La Dispute.

Vygotsky, L. S. (1994). The problem of the environment. The Vygotsky Reader, 338-354.

Whitehead, P. (2011). Evaluation report of research at six community chaplaincy projects. Teesside University.

\section{Websites}

www.communitychaplaincy.org.uk.

www.clinks.org. 
Open Access This chapter is licensed under the terms of the Creative Commons Attribution 4.0 International License (http://creativecommons.org/ licenses/by/4.0/), which permits use, sharing, adaptation, distribution and reproduction in any medium or format, as long as you give appropriate credit to the original author(s) and the source, provide a link to the Creative Commons license and indicate if changes were made.

The images or other third party material in this chapter are included in the chapter's Creative Commons license, unless indicated otherwise in a credit line to the material. If material is not included in the chapter's Creative Commons license and your intended use is not permitted by statutory regulation or exceeds the permitted use, you will need to obtain permission directly from the copyright holder.

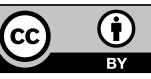

